Original Article

\title{
PREVALENCE AND EXTENT OF AWARENESS OF DEPRESSION IN YOUTH
}

\author{
VISHALKALYANI A. ${ }^{*}$, SUMAN S. RA0 ${ }^{1}$, BARDIA REZAINOEI ${ }^{1}$, R. SRINIVASAN ${ }^{1}$, VINEELA NEKKANTI ${ }^{1}$
}

1Department of Pharmacy Practice, PES College of Pharmacy, Bengaluru, 560050, Karnataka, India

*Email: vishalkalyani@gmail.com

Received: 11 Mar 2021, Revised and Accepted: 20 Apr 2021

\section{ABSTRACT}

Objective: Depression is a common mental disorder that affects hundreds of millions of people worldwide. Increasing awareness about depression in youth can help in addressing the consequences of the disorder that may extend to adulthood. This study aimed to determine the prevalence and associated sociodemographic factors of depression among youth and to determine the efficacy of an educational intervention in increasing awareness about depression.

Methods: Pre-university and graduate students between 15 to 24 y of age were included in the study. Data was collected using the Patient Health Questionnaire-9, the Adolescent Depression Knowledge Questionnaire, and a self-designed proforma of socio-demographic factors. An educational intervention, in the form of a video, was provided to the subjects. A post-intervention questionnaire was administered after a period of 4-6 w. Analysis and interpretation of data were completed using the Chi-square test and SPSS v22 software.

Results: The prevalence of depression in youth was found to be $29.6 \%$ using a PHQ-9 cut-off score of 10 . Annual household income was found to have a statistically significant association with the prevalence of depression (*P-value: 0.036). The students' knowledge about depression was notably improved, as observed from answers of the ADKQ, before and after the educational intervention.

Conclusion: Depression is prevalent among Indian students, and this highlights the need for screening of students and educational interventions. Providing educational interventions to students can increase their awareness and knowledge about depression.

Keywords: Depression, Mental health, Prevalence, Awareness

(c) 2021 The Authors. Published by Innovare Academic Sciences Pvt Ltd. This is an open access article under the CC BY license (https://creativecommons.org/licenses/by/4.0/] DOI: https://dx.doi.org/10.22159/ijpps.2021v13i6.41394. Journal homepage: https://innovareacademics.in/journals/index.php/ijpps.

\section{INTRODUCTION}

Depression is a common mental disorder affecting more than 264 million people worldwide. It may be characterized by persistent sadness, a lack of interest or pleasure in previously rewarding or enjoyable activities, disturbances in sleep and appetite, tiredness, and poor concentration [1]. The estimated prevalence of depression in youth ranges from $3.1 \%-68 \%$ [2].

Today's youth are in a challenging developmental phase with many physical, psychological, cognitive, and social changes. Life events that are likely to affect the appearance of depressive symptoms in youth include failure in examination, serious illness, death of a family member, change in residence, and end of a relationship [3]. Other risk factors include academic stress, having a working mother, familial discord, and economic burden $[2,4]$.

It is known that the trajectories of mental disorders can be modified through their early recognition and intervention [5]. Mental health literacy is defined as knowledge and beliefs about mental disorders that assist in their recognition, management, or prevention. It comprises of components like identification of mental health disorders and knowledge of risk factors, causes, self-treatments, and professional help available. Currently, there is a widespread stigma about mental disorders, and they are sometimes believed to be untreatable, which causes delay or prevention from seeking help [6, 7].

Mental health literacy is vital in adolescents, as about half of those who develop mental disorders as adults have their first episodes before the age of $18 \mathrm{y}$. Knowledge and awareness about depression play a key role in ensuring timely support and treatment of youth with depressive symptoms, thus aiding in the attainment of better outcomes in the future $[8,9]$. Hence, our study was aimed at determining the impact of mental health education in improving mental health literacy in youth.

\section{MATERIALS AND METHODS}

\section{Design and setting}

A prospective observational study was carried out for six months between October 2019 and March 2020. Before the initiation of the study, ethical clearance was obtained from the Institutional Ethical Committee (IEC approval number: PESCP/2019-20/PharmD/04). In addition, permission to use the Adolescent Depression Knowledge Questionnaire (ADKQ) was obtained from Dr Karen Swartz via e-mail.

For subjects to be included in the study, they had to meet the inclusion criteria of being within 15-24 y of age and attending either preuniversity or a degree college. Exclusion criteria were subjects below $15 \mathrm{y}$ of age, subjects above $24 \mathrm{y}$ of age, and subjects not attending preuniversity or Degree College. Data collection was performed using the Patient Health Questionnaire-9 (PHQ-9), the ADKQ, and a self-made proforma of socio-demographic factors. The forms were circulated among the graduate students using a Google Forms link, while the preuniversity students received paper versions of the forms. The procedure for the collection of data was explained to the subjects, and they were ensured of anonymity and confidentiality. Informed consent was obtained from the participants orally. The students entered their student ID numbers. After answering the questions, the participants were shown an informational video that served as the educational intervention. After four to six weeks, the participants answered the ADKQ. 321 students participated in the post-intervention test as opposed to 467 students before the intervention, and thus the former 321 participants' answers before and after the intervention were considered for analysis. The answers of the students before and after receiving the educational intervention were clubbed according to their student ID number, after which a unique ID number was assigned to maintain anonymity.

\section{Measures}

Patient Health Questionnaire-9: The PHQ-9 is a nine-item, selfreport tool that contains DSM-IV criteria along with other major depressive symptoms designed to screen for depression. A score of 0-4 indicates minimal depression, 5-9 indicates mild depression, 1014 indicates moderate depression, 15-19 indicates moderately severe depression, and a score between 20-27 indicates severe depression [10]. For this study, scores greater than or equal to 10 were considered to have high specificity and sensitivity for major depressive disorder. 
Adolescent Depression Knowledge Questionnaire: The ADKQ was designed in conjunction with the Adolescent Depression Awareness Program (ADAP), a school-based, a universal program designed to educate students about depression. The ADAP was developed in 1999 as a means to increase depression literacy and promote helpseeking in students. The fundamental message that it delivers is that depression is a treatable medical illness and help can be sought [5]. It contains a section of 13 closed-ended questions that assess depression literacy, which was used in this study.

Socio-demographic factors: A self-designed proforma which included questions regarding socio-demographic factors such as age, gender, religion, education of parents, working status of parents, family situation (joint or nuclear), and annual income of the family was used.

\section{Sample size and statistical analysis}

The sample size was determined using the standard normal variate at 5\% type I error. The expected proportion was set as $16.5 \%$, obtained from a previous study conducted by Kaur et al. [11], and absolute error was set as 5\%. The sample size was found to be 212 .
Data was transcribed into MS Excel and analysed using Statistical Package for Social Sciences (SPSS) version 22 software. Descriptive statistics, such as frequencies and proportions, were used to describe the socio-demographic factors. A Chi-square test was used to test the association between the factors and depression, as well as to compare students' answers to the ADKQ before and after the educational intervention. A P-value below 0.05 was considered to be statistically significant.

\section{RESULTS AND DISCUSSION}

Table 1: Prevalence of depression among the study subjects

\begin{tabular}{lll}
\hline PHQ-9 score & Frequency & Percent \\
\hline$<10$ & 226 & 70.4 \\
$\geq 10$ & 95 & 29.6 \\
Total & 321 & 100.0 \\
\hline
\end{tabular}

*PHQ-9 score greater than or equal to 10 indicates depression.

Table 2: Association of socio-demographic factors with depression

\begin{tabular}{|c|c|c|c|c|c|}
\hline Demographic data & & Depression score $<10$ & Depression score $\geq 10$ & $\boldsymbol{x}^{2}$ & P-value \\
\hline \multirow[t]{3}{*}{ 1. Age Group } & $15-17 y$ & 67 & 34 & 1.172 & 0.556 \\
\hline & $18-20 y$ & 109 & 42 & & \\
\hline & $20-24 y$ & 50 & 19 & & \\
\hline \multirow[t]{2}{*}{ 2. Gender } & Female & 124 & 49 & 0.291 & 0.590 \\
\hline & Male & 102 & 46 & & \\
\hline \multirow[t]{4}{*}{ 3. Religion } & Christian & 6 & 1 & & \\
\hline & Hindu & 211 & 86 & 3.356 & 0.340 \\
\hline & Muslim & 7 & 6 & & \\
\hline & Other & 2 & 2 & & \\
\hline \multirow[t]{6}{*}{ 4. Father's Education } & Don't know & 5 & 0 & & \\
\hline & Graduate & 103 & 41 & 4.494 & 0.481 \\
\hline & Illiterate & 6 & 5 & & \\
\hline & Primary & 15 & 6 & & \\
\hline & PUC & 60 & 23 & & \\
\hline & Secondary & 37 & 20 & & \\
\hline \multirow[t]{6}{*}{ 5. Mother's Education } & Don't know & 2 & 2 & & \\
\hline & Graduate & 77 & 28 & 9.849 & 0.080 \\
\hline & Illiterate & 5 & 9 & & \\
\hline & Primary & 23 & 9 & & \\
\hline & PUC & 62 & 22 & & \\
\hline & Secondary & 57 & 25 & & \\
\hline \multirow[t]{3}{*}{ 6. Father's Job } & Government job & 28 & 16 & & \\
\hline & Private sector & 188 & 71 & 3.464 & 0.177 \\
\hline & Unemployed & 10 & 8 & & \\
\hline \multirow[t]{3}{*}{ 7. Mother's Job } & Government job & 12 & 9 & & \\
\hline & Private sector & 33 & 18 & 3.192 & 0.203 \\
\hline & $\begin{array}{l}\text { Unemployed/ } \\
\text { Housewife }\end{array}$ & 181 & 68 & & \\
\hline \multirow{4}{*}{$\begin{array}{l}\text { 8. Yearly Household } \\
\text { income }\end{array}$} & Don't know & 50 & 18 & & \\
\hline & Less than Rs. 27 thousand & 18 & 6 & 8.856 & 0.036 \\
\hline & $\begin{array}{l}\text { Between Rs. 27-50 } \\
\text { thousand }\end{array}$ & 16 & 17 & & \\
\hline & More than Rs. 50 thousand & 142 & 54 & & \\
\hline \multirow[t]{2}{*}{ 9. Family System } & Joint family & 35 & 14 & & \\
\hline & Nuclear family (3-5 people) & 191 & 81 & 0.029 & 0.865 \\
\hline
\end{tabular}

The prevalence of depression in previous studies was found to be in the range of 3.1-68\% [2]. This wide range could be due to different factors including the varying instruments that were used to screen for depression. In a cross-sectional study conducted by Kaur et al. on youth, using the PHQ-9, the prevalence of depression was found to be $16.5 \%$ [11], however, the cut-off score was not stated. Our estimate of $29.6 \%$ seems to fall in-between the ranges found by similar studies conducted on Indian students [2] (table 1).

Youth are in a transient phase of academic stress and social changes, and the increasing trends in the prevalence of depression are alarming [12]. Previous studies have found several sociodemographic variables affecting the onset of depression in youth including gender, working status of parents, economic background, and nutritional status [13-16].

The present study aimed to determine factors associated with the prevalence of depression among youth in the country (table 2). Annual household income was found to be significantly associated with the prevalence of depression. According to the Indian Human Developmental Survey, the mean household income in India is Rs. 49,073 , and below poverty line income is Rs. $27,000[17,18]$. In this study, incomes were classified into three groups: below Rs. 27,000, Rs. 27,000-50,000, and above Rs. 50,000. Lower annual household income can indicate a lack of health care, below average schooling 
facilities, food, and other essential needs, thus affecting an individual's mental health. Studies in the past have concluded that lower annual household income is associated with the prevalence of depression [15, 19, 20]. Individuals from lower economic backgrounds may lack self-confidence and self-esteem and may feel less privileged than those from better economic backgrounds [15]. They may even feel deprived of opportunities and experience excessive financial stress, thus hindering their academic and career progress. Increased suicidal ideation was found among adolescents in a previous study due to failure in examination, relationship problems, and financial stress [21]. Among various other sociodemographic factors assessed under this study for their association with the prevalence of depression, the gender difference was not found to be significantly associated with the prevalence of depression. This was similar to previous studies $[13,15]$. This may be due to both genders' experiencing similar amounts of stress and depressive triggers in India, a developing nation. Parents' employment status was studied to understand its association with the prevalence of depression. Previous studies have suggested that the father's unemployment increased the odds of depression, while a mother's lack of employment reduced the odds [15, 22]. However, the present study did not find an association with this factor. Parents' level of educational attainment was studied as it can influence parenting behavior, health care, better schooling, and economic condition, but a significant association with depression was not found in this study $[14,15]$. This is not consistent with prior research which has found that the educational level of parents is closely related to the mental health of students [15, 22]. These differences may be due to cultural variations, which is a consideration in cross-national research.

Table 3: ADKQ questions and responses

\begin{tabular}{|c|c|c|c|c|c|c|c|}
\hline \multirow[t]{2}{*}{ ADKQ questions and responses* } & & \multicolumn{4}{|l|}{ Group } & \multirow[t]{2}{*}{$\varkappa^{2}$} & \multirow[t]{2}{*}{ P-value } \\
\hline & & Pre-test no. & $\%$ & Post-test no. & $\%$ & & \\
\hline \multirow{2}{*}{$\begin{array}{l}\text { 1. Five percent of all teenagers will suffer a major } \\
\text { depression. }\end{array}$} & No & 22 & 06.86 & 31 & 09.66 & \multirow[t]{2}{*}{1.667} & \multirow{2}{*}{0.197} \\
\hline & Yes & 299 & 93.14 & 290 & 90.34 & & \\
\hline \multirow[t]{2}{*}{ 2. Major depression is a normal part of adolescence. } & No & 104 & 32.40 & 125 & 38.95 & \multirow[t]{2}{*}{2.994} & \multirow[t]{2}{*}{0.084} \\
\hline & Yes & 217 & 67.60 & 196 & 61.05 & & \\
\hline \multirow[t]{2}{*}{ 3. Depression runs in some families. } & No & 81 & 25.24 & 73 & 22.74 & \multirow[t]{2}{*}{0.547} & \multirow[t]{2}{*}{0.460} \\
\hline & Yes & 240 & 74.76 & 248 & 77.26 & & \\
\hline \multirow[t]{2}{*}{ 4. Depression can be controlled through willpower. } & No & 47 & 14.64 & 71 & 22.12 & \multirow[t]{2}{*}{5.981} & \multirow[t]{2}{*}{0.014} \\
\hline & Yes & 274 & 85.36 & 250 & 77.88 & & \\
\hline \multirow[t]{2}{*}{ 5. The cause of major depression is well known. } & No & 120 & 37.39 & 133 & 41.43 & \multirow[t]{2}{*}{1.102} & \multirow[t]{2}{*}{0.294} \\
\hline & Yes & 201 & 62.61 & 188 & 58.57 & & \\
\hline \multirow[t]{2}{*}{ 6. A change in behaviour is a symptom of depression. } & No & 74 & 23.06 & 63 & 19.63 & \multirow[t]{2}{*}{1.123} & \multirow[t]{2}{*}{0.289} \\
\hline & Yes & 247 & 76.94 & 258 & 80.37 & & \\
\hline \multirow{4}{*}{$\begin{array}{l}\text { 7. There are certain groups of people who are immune to } \\
\text { depression. } \\
\text { 8. Major Depression is a treatable medical illness. }\end{array}$} & No & 123 & 38.32 & 139 & 43.30 & \multirow[t]{2}{*}{1.651} & \multirow[t]{2}{*}{0.199} \\
\hline & Yes & 198 & 61.68 & 182 & 56.70 & & \\
\hline & No & 111 & 34.58 & 108 & 33.65 & \multirow{2}{*}{0.062} & \multirow{2}{*}{0.803} \\
\hline & Yes & 210 & 65.42 & 213 & 66.35 & & \\
\hline \multirow[t]{2}{*}{ 9. A person with depression always feels sad. } & No & 61 & 19.00 & 80 & 24.92 & \multirow[t]{2}{*}{3.281} & \multirow[t]{2}{*}{0.070} \\
\hline & Yes & 260 & 81.00 & 241 & 75.08 & & \\
\hline \multirow{2}{*}{$\begin{array}{l}\text { 10. The abuse of alcohol and drugs can be a sign of } \\
\text { depression. }\end{array}$} & No & 80 & 24.92 & 80 & 24.92 & \multirow[t]{2}{*}{0.000} & 1.000 \\
\hline & Yes & 241 & 75.08 & 241 & 75.08 & & \\
\hline 11. Bipolar Disorder is more common than Major & No & 149 & 46.42 & 127 & 39.56 & 3.076 & 0.079 \\
\hline Depression. & Yes & 172 & 53.58 & 194 & 60.44 & & \\
\hline 12. Major depression is a curable illness. & No & 75 & 23.37 & 88 & 27.42 & 1.390 & 0.236 \\
\hline & Yes & 246 & 76.63 & 233 & 72.58 & & \\
\hline
\end{tabular}

*Correct answers are marked in bold.

An educational intervention was provided to students to increase awareness and knowledge of depression. The Adolescent Depression Knowledge Questionnaire (ADKQ) was used to assess knowledge before and after the intervention (table 3). The setup was similar to a study conducted by Swartz et al. [5]. There was a notable improvement in the number of correct answers provided by the subjects before and after the educational intervention. The improvement in choosing the correct answer to the question "depression can be controlled by willpower" was found to be statistically significant. This is an indication that such awareness programs can be key to improving knowledge about mental health and enhancing help-seeking behaviour [22, 23]. Simple screening tools like the PHQ-9 can be used in educational institutions for extensive screening for depression and other mental health issues.

Certain study limitations should be acknowledged. Firstly, only the PHQ-9 was used to determine the prevalence of depression, and there was no external criterion such as a clinical interview for validation of the self-report measures. Previous studies suggest that one-stage screening using rating scales usually overestimates the point prevalence of depression. Secondly, the educational intervention was limited to a video lasting six minutes, fairly short, when compared to the Adolescent Awareness Depression Program which includes 180 min of curriculum consisting of videos, lectures, and group activities. Thirdly, because of the lack of a randomized, controlled study design, conclusions about the educational intervention causing the change in answers before and after the intervention cannot be made. However, the temporal relationship and degree of change can make the educational intervention a plausible explanation for the results obtained.

\section{CONCLUSION}

To conclude, the prevalence of depression in youth was estimated to be $29.6 \%$. Among various sociodemographic factors studied, lower annual household income was found to be associated with depression. Lastly, we conclude that providing an awareness program to students can improve knowledge and awareness about depression.

\section{ACKNOWLEDGEMENT}

We thank the following individuals for their expertise, administrative support, and technical assistance throughout our study: Dr. S Mohan (PES College of Pharmacy), Dr. J Saravanan, (PES College of Pharmacy), and Mr. Narayana Reddy (PES Pre-university College).

\section{FUNDING}

Nil

\section{AUTHORS CONTRIBUTIONS}

Vishalkalyani A. conceptualized the study, acquired data, analysed data, and co-wrote the paper. Bardia Rezaeinoei acquired data and 
co-wrote the paper. Suman S Rao acquired data, analysed data, and co-wrote the paper. Dr R Srinivasan helped to facilitate the study, cowrote the paper, and performed critical review. Dr Vineela Nekkanti helped to facilitate the study, co-wrote the paper, and performed critical review.

\section{CONFLICTS OF INTERESTS}

The authors declare that the research was conducted in the absence of any commercial or financial relationships that could be construed as a potential conflict of interest.

\section{REFERENCES}

1. World Health Organization. Health Topics: Depression. Available from: https://www.who.int/health-topics/ depression\#tab=tab_1 [Last accessed on 10 Feb 2021]

2. Grover S, Raju V, Sharma A, Shah R. Depression in children and adolescents: a review of Indian studies. Indian J Psychol Med 2019;41:216.

3. Bostanci M, Ozdel O, Oguzhanoglu NK, Ozdel L, Ergin A, Ergin N, et al. Depressive symptomatology among university students in Denizli, Turkey: prevalence and sociodemographic correlates. Croat Med J 2005:46:96-100.

4. Mohammadi MR, Alavi SS, Ahmadi N, Khaleghi A, Kamali K, Ahmadi A. The prevalence, comorbidity and socio-demographic factors of depressive disorder among Iranian children and adolescents: to identify the main predictors of depression. J Affect Disorder 2019;247:1-10.

5. Swartz K, Musci RJ, Beaudry MB, Heley K, Miller L, Alfes C, et al. School-based curriculum to improve depression literacy among us secondary school students: a randomized effectiveness trial. Am J Public Health 2017;107:1970-6.

6. Jorm AF, Korten AE, Jacomb PA, Christensen H, Rodgers B, Pollitt P. Mental health literacy: a survey of the public's ability to recognise mental disorders and their beliefs about the effectiveness of treatment. Med J Aust 1997;166:182-6.

7. Qassim S, Boura F, Al-hariri Y. Public knowledge and attitude toward depression and schizophrenia: Findings from a quantitative study in UAE. Asian J Pharm Clin Res 2018;11:402.

8. Mousse F, Morrissey H, Ball PA. Exploring university students' perception of stress and stress management during a university health promotion day. Int J Curr Pharm Res 2019;11:93-100.

9. Ogorchukwu JM, Sekaran VC, Nair S, Ashok L. Mental health literacy among late adolescents in South India: what they know and what attitudes drive them. Indian J Psychol Med 2016;38:234-41.

10. Kroenke K, Spitzer RL, Williams JBW. The PHQ-9. J General Internal Med 2001;16:606-13.
11. Kaur S, SS Deepti, Lal Mohan. Prevalence and correlates of depression among college-going students of District Amritsar, India. Int Res J Med Sci 2014;2:5-9.

12. Jha KK, Singh SK, Nirala SK, Kumar C, Kumar P, Aggrawal N. Prevalence of depression among school-going adolescents in an Urban Area of Bihar, India. Indian J Psychol Med 2017;39:28792.

13. Grover S, Dutt A, Avasthi A. An overview of Indian research in depression. Indian J Psychiatry 2010;52 Suppl 1:S178-88.

14. Piko BF, Luszczynska A, Fitzpatrick KM. Social inequalities in adolescent depression: the role of parental social support and optimism. Int J Soc Psychiatry 2012;59:474-81.

15. Chen L, Wang L, Qiu XH, Yang XX, Qiao ZX. Depression among Chinese University students: prevalence and sociodemographic correlates. PLoS One 2013;8:e58379.

16. $\mathrm{Kb} \mathrm{C}, \mathrm{Av} \mathrm{K}, \mathrm{AS}, \mathrm{Sb} \mathrm{T}$. Prescription pattern analysis of antidepressants in psychiatric outpatient department of tertiary care hospital in India. Asian J Pharm Clin Res 2016;143:77-9.

17. Balchand K, Sunderajan P. You will be on BPL list if your annual income is Rs.27,000. Hindu; 2011. Available from: https://www.thehindu.com/news/national/you-will-be-onbpl-list-if-your-annual-income-is-rs27000/article2035893.ece. [Last accessed on $10 \mathrm{Feb} 2021$ ]

18. Desai Sonalde, Amaresh Dubey, BL Joshi, Mitali Sen, Abusaleh Shariff, Reeve Vanneman. Human development in India: challenges for a society in transition. New Delhi: Oxford University Press; 2010. p. 234.

19. Bayram N, Bilgel N. The prevalence and socio-demographic correlations of depression, anxiety and stress among a group of university students. Soc Psychiatry Psychiatr Epidemiol 2008;43:667-72.

20. Steptoe A, Tsuda A, Tanaka Y, Wardle J. Depressive symptoms, socio-economic background, sense of control, and cultural factors in university students from 23 countries. Int J Behav Med 2007;14:97-107.

21. Ovuga E, Boardman J, Wasserman D. Undergraduate student mental health at Makerere University, Uganda. World Psychiatry 2006;5:51-2.

22. Daniel Graeber, Daniel D Schnitzlein. "The effect of maternal education on offspring's mental health," SOEPpapers on multidisciplinary panel data research 1028, DIW berlin, the german socio-economic panel (SOEP); 2019.

23. Ingunn Skre, Oddegeir Friborg, Camilla Breivik. A school intervention of mental health literacy in adolescents: effects of a non-randomized cluster-controlled trial. BMC Public Health 2013;13:873. 